\title{
جامعة الأزهر
}

كلية اللغة العربية بالزقازيق

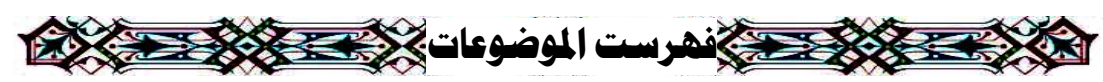

\begin{tabular}{|c|c|c|}
\hline رقم الصفحة & الموضوع & مسسلسل \\
\hline - & 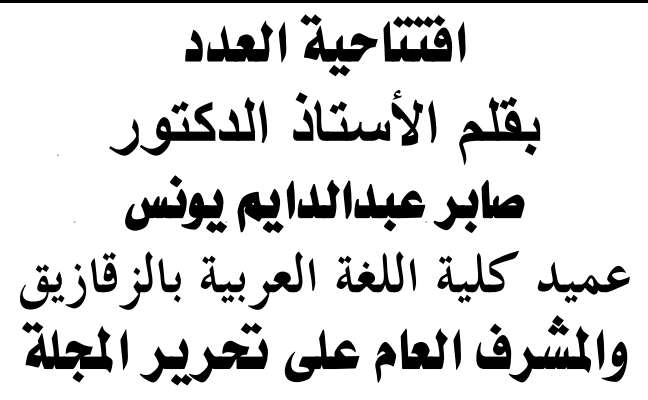 & 1 \\
\hline & قسم الأدب والنـــــــ & \\
\hline 1.VE_A00 & 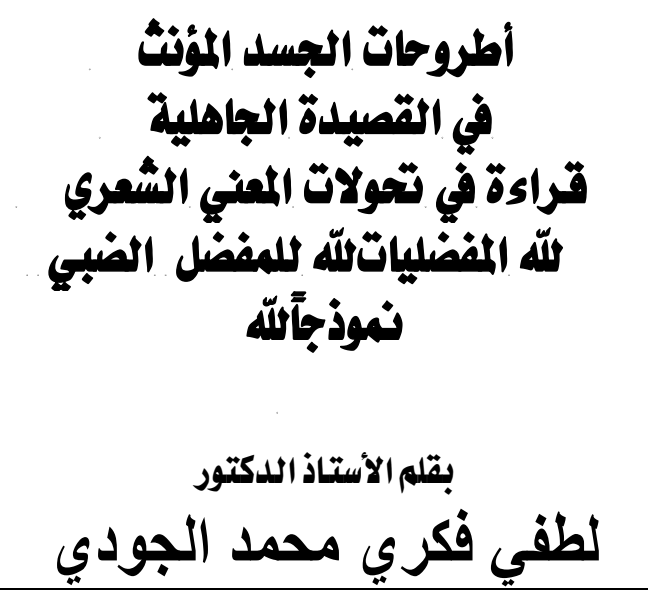 & $r$ \\
\hline IIAY_I.VO & 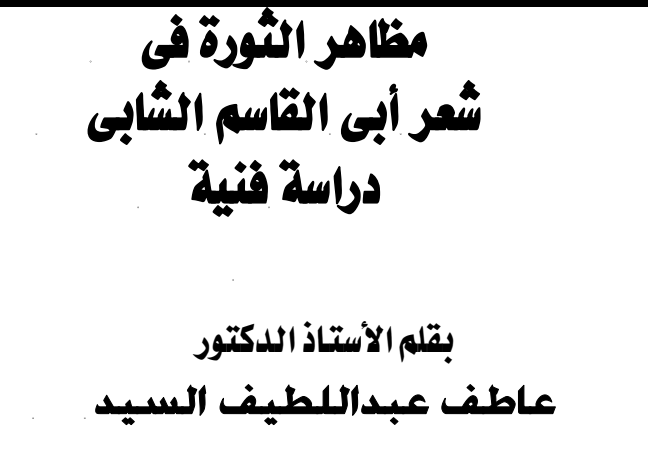 & $r$ \\
\hline
\end{tabular}




\section{جامعة الأزهر}

كلية اللغة العربية بالزقازيق

\begin{tabular}{|c|c|c|}
\hline رقم الصفحة & الموضوع & مساسل \\
\hline MAE_HAT & قسي البلافة والنقد & $\xi$ \\
\hline |rEz_I110 & 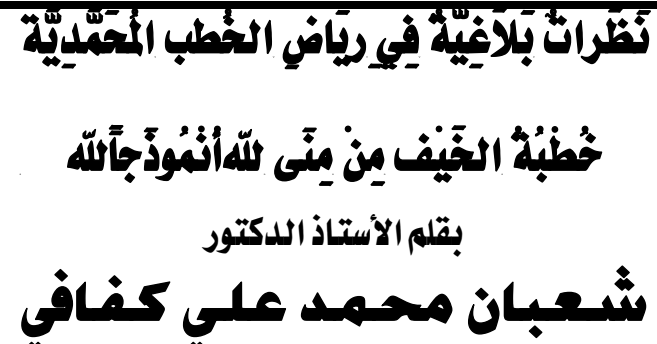 & 0 \\
\hline ITYY_IT\&O & 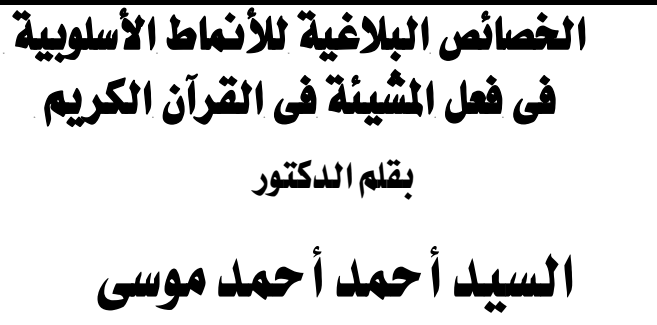 & 7 \\
\hline IETY_ITYK & 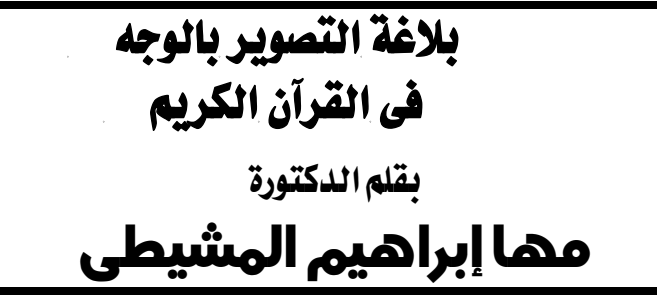 & $r$ \\
\hline lorg_IETr & 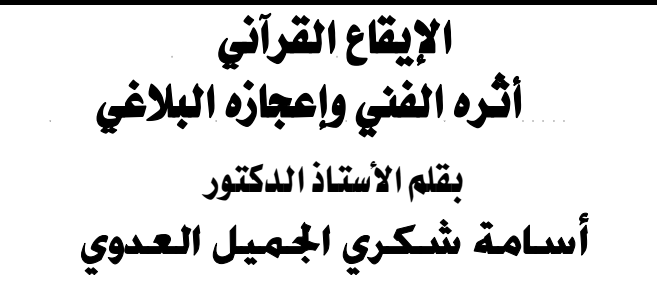 & $\Lambda$ \\
\hline IOYA_IOYY & قسم أصول اللغة & 9 \\
\hline lorr_lora & 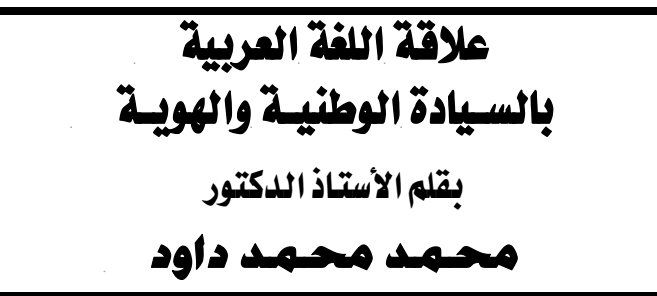 & 1. \\
\hline
\end{tabular}




\section{جامعة الأزهر}

كلية اللغة العربية بالزقازيق

\begin{tabular}{|c|c|c|}
\hline رقم الصفحّة & الموضوع & مسساسل \\
\hline lov\&_lovr & 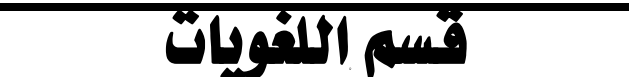 & 11 \\
\hline 17FA_-10VO & اللفات الضصيفة وأُُرها في أصول النهو & ir \\
\hline IVYY_Ifra & 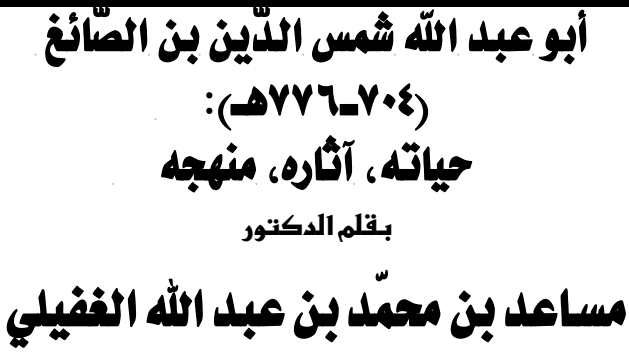 & \\
\hline $19 \cdots \_$Irrv & 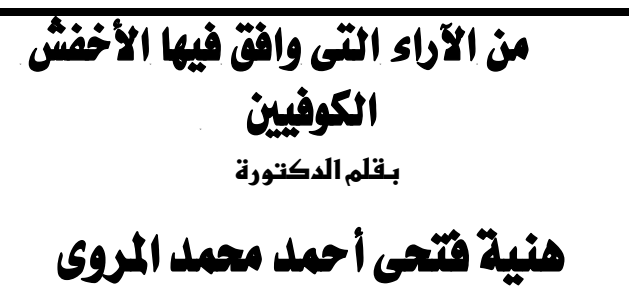 & \\
\hline $19 \cdot \xi-19 \cdot 1$ & فهرس الموضوعات & \\
\hline
\end{tabular}




$$
\text { كلية اللغة العربية بالزقازيق }
$$

\section{العدد الثالثُ والثُلاثون عباهـ_ rا.rrم

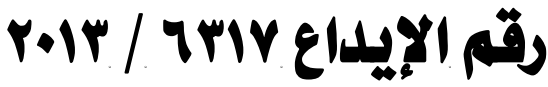

